
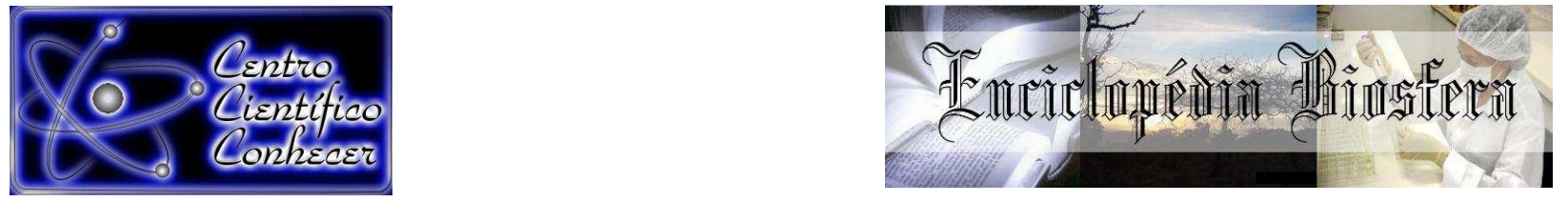

\title{
ANÁLISE ECONÔMICA DO CULTIVO DE ARROZ IRRIGADO POR ASPERSÃO SOB DIFERENTES MANEJOS DO SOLO, DOSES DE NITROGÊNIO E INOCULAÇÃO COM Azospirillum brasilense
}

Flávia Constantino Meirelles ${ }^{1}$, Orivaldo Arf $^{2}$, Douglas de Castilho Gitti ${ }^{3}$, Alex Rangel Gonzaga $^{4}$, Caike de Souza Silva Silvério ${ }^{1}$

1. Graduanda em Agronomia na Universidade Estadual Paulista "Julio de Mesquita

Filho" FE - Ilha Solteira - SP - Brasil (flavia.meirelles1905@gmail.com).

2. Professor do curso de Agronomia na Universidade Estadual Paulista "Julio de Mesquita Filho" FE - Ilha Solteira - SP - Brasil

3. Pesquisador Fundação MS - Maracajú - MS - Brasil

4. Engenheiro Agrônomo graduado pela Universidade Estadual Paulista "Julio de Mesquita Filho" FE - Ilha Solteira - SP - Brasil

Recebido em: 08/09/2015 - Aprovado em: 14/11/2015 - Publicado em: 01/12/2015 DOI: http://dx.doi.org/10.18677/Enciclopedia_Biosfera_2015_083

\section{RESUMO}

O arroz é um dos cereais mais cultivados em todo mundo, nos mais diferentes sistemas. Práticas de manejo de solo, irrigação, maneiras de fornecimento de nitrogênio e inoculação de sementes com bactérias diazotróficas, são alguns fatores que podem alavancar a produtividade da cultura do arroz. Assim, o objetivo do trabalho foi fazer uma análise econômica verificando o melhor tratamento e a viabilidade para o produtor, na produção de arroz de terras altas irrigado por aspersão, associada a diferentes manejos do solo, doses de $\mathrm{N}$ e inoculação com Azospirillum brasilense. O experimento foi desenvolvido no município de Selvíria (MS), durante o ano agrícola 2012/13, em área experimental da UNESP llha Solteira - SP. O delineamento foi em blocos casualizados em esquema fatorial $2 \times 4 \times 2$, com quatro repetições, sendo constituído de preparos de solo (sistema plantio direto e grade pesada + grade niveladora), doses de $\mathrm{N}\left(0,40,80,120 \mathrm{~kg} \mathrm{~N} \mathrm{ha}^{-1}\right)$ e com ou sem inoculação de Azospirillum brasilense. Pode-se verificar que a medida que se aumenta as doses de $\mathrm{N}$ aumenta-se o Custo Operacional Total, sendo os insumos e as operações mecanizadas os fatores que mais contribuem para o Custo Operacional Total. O sistema plantio direto mostrou resultados econômicos satisfatórios quando comparados ao preparo convencional e a maior lucratividade foi obtida no sistema plantio direto com adubação nitrogenada na dose de $40 \mathrm{~kg} \mathrm{ha}^{-1}$ de $\mathrm{N}$ sem inoculação de Azospirillum brasilense na semente.

PALAVRAS-CHAVE: bactérias diazotróficas, Oryza sativa L., preparo convencional, sistema plantio direto, uréia 


\title{
LAND RICE HIGH IRRIGATION SPRINKLER UNDER DIFFERENT SOIL MANAGEMENTS, NITROGEN DOSES AND INOCULATION WITH Azospirillum brasilense: ECONOMIC ANALYSIS
}

\begin{abstract}
The rice, by being consider one of the most cultivated cereal in the world, in many different systems. Soil tillage practices, irrigation, ways of nitrogen supply and inoculating seeds with nitrogen fixing bacteria, are some factors that can boost the productivity of rice cultivation. The objective of this study was to make an economic analysis by checking the best treatment and the viability for the producer in the production of high rice irrigated by sprinkler, associated with different managements of the soil, nitrogen doses and inoculation with Azospirillum brasilense. The experiment was conducted in Selvíria (MS) during the 2012/13 growing season in the experimental area UNESP Ilha Solteira - SP. The design was randomized blocks in a factorial design $2 \times 4 \times 2$, with four replications, consisting of soil tillage (no-till and heavy harrow + disking), $\mathrm{N}$ rates $(0,40,80,120 \mathrm{~kg} \mathrm{~N}$ ha-1) and with or without inoculation of Azospirillum brasilense. It can be seen that as one increases the doses of $\mathrm{N}$ increases the Total Operating Costs, and the inputs and mechanized operations the factors that contribute most to Total Operating Costs. The no-tillage system showed satisfactory economic results compared to conventional tillage and the highest profitability was achieved at the till system with nitrogen fertilizer at the rate of $40 \mathrm{~kg} \mathrm{ha}^{-1} \mathrm{~N}$ without inoculation of Azospirillum brasilense in the seed.
\end{abstract}

KEYWORDS: Oryza sativa L., conventional tillage, diazotrophic bacteria, no tillage system, urea

\section{INTRODUÇÃO}

O arroz é um dos cereais mais cultivados com uma produção superior a 738 milhões de toneladas e uma produtividade média ao redor de $4.540 \mathrm{~kg} \mathrm{ha}^{-1}$ (FAO, 2013). No Brasil, a área cultivada na safra 2014/15 foi menor em relação à safra 2013/14, aproximadamente 2.312 milhões de hectares, mesmo com uma menor área, a cultura obteve aumento de produção e produtividade de $3,5 \%$ e $6,2 \%$ respectivamente, sendo a produção de mais de 12,54 milhões de toneladas, e a produtividade de $5.425 \mathrm{~kg} \mathrm{ha}^{-1}$ (CONAB, 2015a). Rio Grande do Sul é o Estado maior produtor, representando quase $70 \%$ da produção nacional.

No Brasil existem três diferentes formas de produção, sendo a produção de arroz irrigado por inundação, arroz irrigado por aspersão e arroz sem irrigação, na qual a água é provém da precipitação. No final da década de 80 , o arroz de terras altas ocupava aproximadamente $80 \%$ da área de produção de arroz, respondendo por mais da metade da produção. Ao longo de 20 anos (período correspondente a 1988-2008), o arroz de terras altas teve sua área de cultivo reduzida em $70 \%$, sua produção diminuída em $55 \%$ e sua produtividade elevada em 49\% (WANDER, 2010).

O sistema irrigado por aspersão vem como uma alternativa para solucionar o problema de veranicos, visto que a lâmina de irrigação confere à cultura estabilidade para sua produção, podendo aumentar a produtividade e melhorar a qualidade do grão produzido (ARF et al., 2012).

Em relação ao valor socioeconômico, o arroz tem grande importância mundial principalmente em países em desenvolvimento, por ser um dos alimentos básicos 
para a população. Além disso, para países da América Latina, o arroz tem destaque por ser um produto comercializado internacionalmente, tanto para exportação quanto para importação. Porém, essa cultura apresenta baixa rentabilidade, uma vez que os custos de produção são elevados (EMBRAPA, 2005). Para aumentar a rentabilidade ao produtor é necessário que haja aumento na produtividade da cultura ou diminuição nos custos de produção.

Dentre os fatores relacionados às melhorias para alavancar a produtividade da cultura do arroz, encontra-se o manejo do solo. As práticas de manejo de solo modificam a estrutura do solo, alterando suas propriedades físicas, tais como umidade, volume, densidade, resistência a penetração, etc (EMBRAPA, 2006).

O revolvimento e a pulverização do solo, causado pelo preparo convencional, produz uma camada de solo mais fina, deixando a estrutura mais solta, em comparação ao sistema plantio direto (SPD), sendo este uma medida conservacionista do solo. Estas diferenças resultam numa mudança de forma, na quantidade e na distribuição de poros, que controlam a capacidade do solo em armazenar água, ar, inferindo na capacidade de crescimento da cultura. O sistema plantio direto, por ser caracterizado como um método conservacionista auxilia no controle da erosão e no desempenho da cultura. As alterações na resistência à penetração do solo afetam a emergência de plântulas, a densidade populacional, a distribuição radicular e a produtividade da cultura (KHAN et al., 2001).

ACQUA, et al. (2013) avaliando amostras de solos em áreas sob plantio direto, concluíram que o sistema plantio direto provoca, no solo, uma concentração de fertilidade superficial para os macronutrientes, exceto o $\mathrm{S}$, devido à calagem, deposição de palhada e adubação superficial.

Associado ao correto manejo de solo, deve-se fornecer nutrientes de forma adequada a cultura, um dos nutrientes necessários a produção da cultura é o nitrogênio $(N)$, nutriente determinante para o crescimento, desenvolvimento e rendimento das plantas, influenciando os processos fisiológicos essenciais da planta. Seu suprimento se dá das mais diversas formas, como: fornecimento através de adubações minerais, adubações orgânicas e através da fixação biológica (BASI et al., 2011). A fixação biológica vem ganhando destaque devido a economia gerada por parte do agricultor em obter parte da adubação nitrogenada oriunda do processo biológico, economizando com a adubação mineral.

Segundo SOARES (2009), a inoculação gera melhor aproveitamento do nitrogênio pelas plantas, sobretudo pelo fato de não existirem perdas do $\mathrm{N}$ fixado, como ocorre em fertilizantes minerais. FANCELLI (2010) relata que no Brasil, a inoculação de sementes com bactérias diazotróficas pode gerar ao agricultor uma economia de 30 a $50 \mathrm{~kg} \mathrm{ha}^{-1}$ de nitrogênio na forma de adubo mineral. Sendo assim, o presente trabalho teve como objetivo verificar a viabilidade econômica da produção de arroz de terras altas irrigado por aspersão, associando a diferentes manejos do solo, doses de $\mathrm{N}$ e inoculação com Azospirillum brasilense.

\section{MATERIAL E MÉTODOS}

O experimento foi desenvolvido no município de Selvíria (MS), durante o ano agrícola 2012/13, em área experimental da Fazenda de Ensino, Pesquisa e

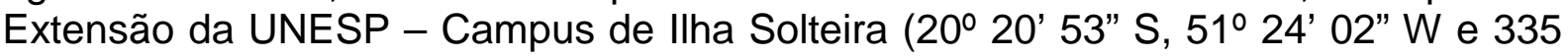
$\mathrm{m}$ de altitude). O solo local é do tipo Latossolo Vermelho distrófico argiloso, classificado por DEMATTÊ (1980) assim como é sua classificação utilizando o Sistema Brasileiro de Classificação de Solos proposta pela EMBRAPA (2013). A 
precipitação média anual é de $1.370 \mathrm{~mm}$, a temperatura média anual é de $23,5{ }^{\circ} \mathrm{C}$ e a umidade relativa do ar entre 70 e $80 \%$ (média anual).

O delineamento do projeto foi em blocos ao acaso, composto por dezesseis tratamentos dispostos em esquema fatorial $2 \times 4 \times 2$, os quais consistiram da combinação dos fatores manejo do solo, doses de $\mathrm{N}$ em cobertura com e sem inoculação de sementes com Azospirillum brasilense. Os sistemas de manejo do solo foram: preparo com grade pesada + grade niveladora e sistema plantio direto (SPD). As doses de $\mathrm{N}$ em cobertura: 0 (sem aplicação de $\mathrm{N}$ ); 40; 80 e $120 \mathrm{~kg} \mathrm{ha}^{-1}$. Presença e ausência da inoculação de sementes com Azospirillum brasilense, com quatro repetições. Como fonte nitrogenada, foi utilizada a ureia ( $45 \%$ de $\mathrm{N}$ ) e como inoculante foi utilizado produto turfoso (estirpes $A_{b V}$ e $A_{b V}$ ) na dose de $100 \mathrm{~g}$ do produto comercial para cada $25 \mathrm{~kg}$ de sementes.

O espaçamento entrelinhas foi de $0,35 \mathrm{~m}$ e a densidade de semeadura foi de $80 \mathrm{~kg} \mathrm{ha}^{-1}$ de sementes, cada parcela foi constituída por cinco linhas de seis metros de comprimento. A área útil considerada foram as três linhas centrais, sendo as linhas laterais consideradas como bordadura.

A área experimental estava com os sistemas de manejo do solo instalados desde o ano agrícola de 1997/98. No período de verão de 2008/09, 2009/10 e 2010/11 a área foi cultivada com milho e 2011/12 com arroz (Tabela 1). No inverno de 2008/09 a área ficou em pousio e nos anos agrícolas 2009/10, 2010/11, 2011/12 e 2012/13 foi cultivada com crotalária para a rotação de culturas e produção de palha no SPD, permanecendo por quatro anos agrícolas no mesmo local de cultivo.

TABELA 1. Histórico da área experimental durante os anos agrícolas 2008/09, 2009/10, 2010/11 e 2011/12. Selvíria, MS, 2012.

\begin{tabular}{cccc}
\hline \multirow{2}{*}{ Ano Agrícola } & \multicolumn{3}{c}{ Estação } \\
\cline { 2 - 4 } & Primavera & Verão & Inverno \\
\hline $\mathbf{2 0 0 8 / 0 9}$ & Pousio & Milho & Pousio \\
$\mathbf{2 0 0 9 / 1 0}$ & Crotalária & Milho & Pousio \\
$\mathbf{2 0 1 0 / 1 1}$ & Crotalária & Milho & Pousio \\
$\mathbf{2 0 1 1 / 1 2}$ & Crotalária & Arroz & Feijão \\
$\mathbf{2 0 1 2 / 1 3}$ & Crotalária & Arroz & Feijão \\
\hline
\end{tabular}

No inverno do ano agrícola 2012/13 foi cultivado feijão. Antes do cultivo do arroz, na mesma área foi cultivada como planta de cobertura Crotalaria juncea, durante 60 dias no período da primavera. Após quatro dias da dessecação da cobertura vegetal (crotalária) foi realizado na área uma operação com desintegrador mecânico do tipo Triton® e posteriormente realizado o preparo do solo em 13 de novembro de 2012. O preparo do solo com grade pesada + grade niveladora, foi realizado com grade pesada à profundidade de $0,20 \mathrm{~m}$ e com grade leve a profundidade de $0,10 \mathrm{~m}$, respectivamente. O manejo no SPD foi restrito somente a desintegração mecânica da cobertura vegetal.

Foi utilizado o cultivar de arroz IAC 202, sendo um cultivar recomendado para arroz de terras altas no estado de São Paulo, apresentando algumas características agronômicas como: arquitetura moderna, porte baixo, grãos finos e longos, produtividade média ao redor de $4.349 \mathrm{~kg} \mathrm{ha}^{-1}$ com potencial para $6.356 \mathrm{~kg} \mathrm{ha}^{-1}$, o que confere uma maior receita bruta pelo potencial produtivo, apresenta altura média de $87 \mathrm{~cm}$, conferindo uma adaptabilidade a colheita mecânica. A semeadura foi realizada no dia 19 de novembro de 2012. As sementes foram tratadas pouco antes 
da semeadura com inseticida (fipronil $50,0 \mathrm{~g}$ i.a. $/ 100 \mathrm{~kg}$ de sementes) visando 0 controle de cupins e lagarta-elasmo. Após a secagem do produto químico nas sementes foi realizada a inoculação com Azospirillum brasilense, e logo após realizou-se a semeadura em solo com boa umidade.

A adubação básica nos sulcos de semeadura foi realizada utilizando-se 250 $\mathrm{kg} \mathrm{ha}{ }^{-1}$ da formulação 04-30-10 (NPK), levando-se em consideração as características químicas do solo e a faixa de produtividade esperada para os cálculos. A adubação nitrogenada em cobertura foi realizada aos 23 dias após a emergência (DAE) das plantas e logo após a aplicação do fertilizante, a área foi irrigada para evitar perdas de $\mathrm{N}$ por volatilização. Foram utilizados herbicidas em pré-emergência (pendimenthalin, $1.400 \mathrm{~g} \mathrm{ha}^{-1}$ do i.a.) e em pós-emergência (metsulfuron-methil, $2 \mathrm{~g}$ ha $^{-1}$ do i.a.) aplicados em 20 de novembro de 2012 e 2,4 D (867 $\mathrm{g} \mathrm{ha}^{-1}$ do i.a.) no dia 2 de janeiro de 2013.

Foram feitas duas aplicações de trifloxystrobina+tebuconazol $(100 \mathrm{~g}+200 \mathrm{~g}$ ha $^{-1}$ do i.a.), sendo a primeira no dia primeiro de fevereiro de 2013 e a segunda no dia 16 de fevereiro de 2013 com o objetivo de prevenir possível ocorrência de brusone.

No manejo de água da cultura do arroz foram utilizados três coeficientes de cultura (Kc), distribuídos em quatro períodos compreendidos entre a emergência e a colheita. Para a fase vegetativa foi utilizado o valor de 0,4 ; para a fase reprodutiva dois coeficientes de cultura (Kc), o inicial de 0,70 e o final de 1,00 e para a fase de maturação estes valores foram invertidos, ou seja, o inicial de 1,00 e o final de 0,70.

A colheita foi realizada quando as plantas de arroz apresentavam $90 \%$ das panículas maduras com coloração típica do cultivar. Os resultados de produtividade obtidos foram submetidos ao teste $F$ da análise de variância. Ao apresentar resultado significativo pelo teste $\mathrm{F}$, foi realizada a comparação de médias pelo teste de Tukey para sistemas de manejo do solo e formas de inoculação com Azospirillum brasilense. $O$ programa estatístico utilizado nas análises foi o Sisvar (FERREIRA, 2008).

O método para análise econômica seguiu o modelo utilizado pelo Instituto de Economia Agrícola, proposto por MATSUNAGA et al. (1976). Foi considerado como custo operacional efetivo (COE) as despesas com operações mecanizadas e os insumos. Acrescentado ao COE outras despesas, incluindo a taxa de administração, obteve-se o custo operacional total (COT), obtido utilizando a fórmula COT $=\mathrm{COE}+$ outras despesas.

Para calcular os custos das operações mecanizadas foram feitos levantamentos de coeficientes técnicos e multiplicados pelo valor apresentado no AGRIANUAL (2015). Para os custos com insumos foram utilizados os preços médios da região e para outras despesas (taxa de administração) foi utilizado $5 \%$ do COE, conforme MARTIN et al. (1998).

A metodologia de MARTIN et al. (1998) foi utilizada para obter os indicadores de lucratividade. A receita bruta $(R B)$ foi calculada considerando a quantidade de arroz em casca produzido ( $Q)$ e o preço médio deflacionado $(R \$ 44,16)$ da saca $(P)$ dos últimos cinco anos (maio de 2010 a maio de 2015) (IEA, 2015), utilizando a fórmula $R B=Q \times P$. O lucro operacional (LO) foi obtido pela diferença da receita bruta e o custo operacional total, considerando a fórmula LO = RB - COT e o índice de lucratividade (IL), expresso em porcentagem, foi obtido pela divisão do lucro operacional pela receita bruta, através da fórmula $\mathrm{IL}=(\mathrm{LO} / \mathrm{RB}) \times 100$. O preço de equilíbrio (Peq), isto é, o preço mínimo que o produtor precisa receber para cobrir os 
custos de produção do arroz, foi calculado pela relação entre o custo operacional total e a produtividade média (prod.) obtida pelo produtor, considerando a fórmula Peq $=$ COT/prod. Para a produtividade de equilíbrio (ProdE) foi feita a relação entre o custo operacional total e o preço médio recebido pelo produtor, utilizando a fórmula ProdE = COT/P.

\section{RESULTADOS E DISCUSSÃO}

O detalhamento da estimativa do custo operacional efetivo e custo operacional total da produção de arroz, para o tratamento com sistema plantio direto, com inoculação de Azospirillum brasilense na semente e com adubação de cobertura na dose de $40 \mathrm{~kg}$ de $\mathrm{N} \mathrm{ha}^{-1}$, encontram-se na Tabela 2. Foi possível observar que a maior porcentagem do COT foi devido aos insumos, representando $51,36 \%$, seguido das operações mecanizadas $(43,88 \%)$, concordando com EMBRAPA (2009) que obteve maiores custos com insumo em arroz de terras altas em área nova e em área em sucessão a pastagem ou soja. Os gastos apenas com pulverização, irrigação, colheita e fertilizantes corresponderam a $61 \%$ do COT, sendo estes as principais variáveis que oneram a cultura.

TABELA 2. Estimativa do Custo Operacional Efetivo e Custo Operacional Total em arroz de terras altas irrigado por aspersão para o tratamento em sistema plantio direto, com adubação em cobertura na dose de $40 \mathrm{~kg}$ de $\mathrm{N} \mathrm{ha}^{-1}$, com inoculação de Azospirillum brasilense na semente.

\begin{tabular}{|c|c|c|c|c|c|}
\hline Descrição & Especificação & $\begin{array}{c}\text { № } \\
\text { vezes }\end{array}$ & Quant. & $\begin{array}{c}\text { Valor } \\
\text { unitário }\end{array}$ & $\begin{array}{c}\text { Total } \\
\text { (R\$) }\end{array}$ \\
\hline
\end{tabular}

\begin{tabular}{lcrrrr}
\hline A. Operações mecanizadas & & & & & \\
\hline Semeadura e adubação & $\mathrm{HM}$ & 1,00 & 0,60 & 115,00 & 69,00 \\
Pulverizações & $\mathrm{HM}$ & 5,00 & 0,80 & 80,00 & 320,00 \\
Adubação de cobertura & $\mathrm{HM}$ & 1,00 & 0,50 & 60,00 & 30,00 \\
Irrigação & $\mathrm{R} / \mathrm{mm}$ & 1,00 & 100,00 & 2,48 & 248,00 \\
Colheita & $\mathrm{HM}$ & 1,00 & 0,50 & 290,00 & 145,00 \\
\hline Subtotal A & & & & & $\mathbf{8 1 2 , 0 0}$ \\
\hline & & & & & \\
\hline B - Insumos & & & & & \\
\hline Sementes & $\mathrm{Sc}$ & 1,00 & 2,00 & 75,00 & 150,00 \\
Adubo (4-30-10) & $\mathrm{T}$ & 1,00 & 0,25 & $1.638,00$ & 409,50 \\
Ureia & $\mathrm{T}$ & 1,00 & 0,04 & $1.538,00$ & 61,52 \\
Fipronil & $\mathrm{Kg}$ & 1,00 & 0,06 & 680,00 & 42,50 \\
Pendimenthalin & $\mathrm{L}$ & 1,00 & 2,80 & 27,90 & 78,12 \\
Metsulfuron methyl & $\mathrm{kg}$ & 1,00 & 0,0033 & 89,00 & 0,29 \\
2,4D & $\mathrm{I}$ & 1,00 & 1,08 & 13,9 & 15,01 \\
Trifloxistrobina+trebuconazol & $\mathrm{I}$ & 2,00 & 0,75 & 112,00 & 168,00 \\
Inoculante & $\mathrm{kg}$ & 1,00 & 0,32 & 80,00 & 25,60 \\
\hline Subtotal B & & & & & 950,55
\end{tabular}

Subtotal B

950,55

Custo operacional efetivo

(COE)

$1.762,55$

Outras despesas

88,13

Custo operacional total

(COT)

$1.850,67$

ENCICLOPÉDIA BIOSFERA, Centro Científico Conhecer - Goiânia, v.11 n.22; p.225 2015 
Em todos os tratamentos foi possível verificar que a maior parte do custo foi em relação aos insumos, com exceção do tratamento com preparo de solo convencional, com $0 \mathrm{~kg}$ de $\mathrm{N} \mathrm{ha}^{-1}$, sem inoculação na semente. Nesse tratamento observou-se maior porcentagem do COT para as operações mecanizadas, obtendo assim resultado semelhante com o trabalho de SILVA \& WANDER (2014) que também encontraram maior porcentagem do COT para as operações mecanizadas, seguida dos insumos. Em relação ao custo dos insumos, o fertilizante foi o que mais contribui para o custo dos insumos $(49,55 \%)$, seguido dos defensivos $(31,97 \%)$, da semente $(15,78 \%)$ e do inoculante $(2,70 \%)$.

Assim os maiores custos de operações mecanizadas foram em relação às pulverizações e à irrigação, corroborando com a CONAB (2015b), que afirma que a quantidade de insumos e aplicações, assim como o aumento da energia elétrica influencia de forma negativa na lucratividade do produtor de arroz.

Para a produtividade do arroz (tabela 3) é possível verificar que o valor desta no sistema plantio direto foi significativamente superior ao preparo convencional do solo. Isso ocorre pois no sistema plantio direto ocorre a permanência da palhada em cobertura, aumentando assim a disponibilidade de nutrientes para as plantas (MUZILLI, 2001).

TABELA 3. Valores médios da produtividade obtidos nos tratamentos manejo do solo, inoculação de sementes e doses de nitrogênio. Selvíria, MS, 2012/13.

\begin{tabular}{|c|c|}
\hline Tratamentos & Produtividade $\left(\mathrm{kg} \mathrm{ha}^{-1}\right)$ \\
\hline $\begin{array}{l}\text { Manejo do solo } \\
\text { SPD } \\
\text { GP + GN }\end{array}$ & $\begin{array}{l}3.914 a \\
2.492 b\end{array}$ \\
\hline \multicolumn{2}{|l|}{ Inoculação } \\
\hline $\begin{array}{l}\text { Presença } \\
\text { Ausência }\end{array}$ & $\begin{array}{l}3.069 \\
3.336\end{array}$ \\
\hline \multicolumn{2}{|l|}{ Doses de N $\left(\mathrm{kg} \mathrm{ha}^{-1}\right)$} \\
\hline 0 & 3.282 \\
\hline 40 & 3.282 \\
\hline 80 & 3.109 \\
\hline 120 & 3.138 \\
\hline \multicolumn{2}{|l|}{ Teste F } \\
\hline Manejo (M) & $69,18^{* *}$ \\
\hline Inoculação(I) & $2,44^{\mathrm{ns}}$ \\
\hline Doses (D) & $0,29^{\text {ns }}$ \\
\hline $\mathrm{M}^{*} \mathrm{I}$ & $1,98^{\mathrm{ns}}$ \\
\hline$M^{*} D$ & $2,92^{\mathrm{ns}}$ \\
\hline$D^{*} \mid$ & $0,21^{\mathrm{ns}}$ \\
\hline$M^{\star} I^{\star} D$ & $0,47^{\text {ns }}$ \\
\hline \multicolumn{2}{|l|}{ DMS } \\
\hline$M$ & 344 \\
\hline I & - \\
\hline CV\% & 21 \\
\hline
\end{tabular}


O COT é maior conforme o aumento das doses de $\mathrm{N}$, com maiores valores na presença de inoculação (Tabela 4). Quando se comparou o sistema plantio direto com o preparo convencional do solo, notou-se que o preparo convencional apresenta maiores valores para o COT. Isso ocorreu devido ao fato de que nesse tratamento é necessário realizar duas operações mecanizadas a mais (gradagem pesada e gradagem niveladora) que no sistema plantio direto.

Para produtividade e para a receita bruta no sistema plantio direto não houve diferença em relação aos tratamentos com e sem inoculação, porém os valores foram maiores para as doses de 40 e $120 \mathrm{~kg}$ de $\mathrm{N}^{-1}$ ha (Tabela 4). Já no preparo convencional do solo, essas duas características foram um pouco superiores para os tratamentos com inoculação quando comparados aos tratamentos sem e também para adubação nas doses de 0 e $80 \mathrm{~kg}$ de N ha ${ }^{-1}$. A produtividade e a receita bruta do sistema plantio direto sempre foram superiores ao preparo convencional, independente do tratamento, discordando do trabalho de FONSECA et al. (2012) que verificaram maior produtividade no preparo convencional quando comparado ao sistema plantio direto na safra 2004/05, talvez esse resultado tenha sido obtido pelo fato do plantio direto ainda estava em fase de implantação diferente do presente trabalho onde o sistema plantio direto já se encontrava consolidado.

TABELA 4. Custo operacional total (COT), produtividade e receita bruta por hectare para arroz de terras altas com doses de nitrogênio e inoculação de $A$. brasilense. Selvíria, MS. Safra 2012/13.

\begin{tabular}{|c|c|c|c|c|c|}
\hline $\begin{array}{l}\text { Preparo do } \\
\text { solo }\end{array}$ & Tratamentos & $\begin{array}{l}\text { Doses de } \\
\mathrm{N}(\mathrm{kg} \text { ha } \\
\text {, }\end{array}$ & COT $(R \$)$ & $\begin{array}{l}\text { Produtividade } \\
\quad\left(\mathrm{kg} \mathrm{ha}^{-1}\right)\end{array}$ & $\begin{array}{c}\text { Receita } \\
\text { bruta }(R \$)\end{array}$ \\
\hline \multirow{8}{*}{$\begin{array}{l}\text { Sistema } \\
\text { Plantio Direto }\end{array}$} & \multirow{4}{*}{$\begin{array}{l}\text { Sem } \\
\text { inoculação }\end{array}$} & 0 & $1.759,20$ & 3.798 & $2.759,20$ \\
\hline & & 40 & $1.823,79$ & 4.205 & $3.094,88$ \\
\hline & & 80 & $1.888,39$ & 3.587 & $2.640,03$ \\
\hline & & 120 & $1.952,98$ & 4.117 & $3.030,11$ \\
\hline & \multirow{4}{*}{$\begin{array}{c}\text { Com } \\
\text { inoculação }\end{array}$} & 0 & $1.786,08$ & 3.748 & $2.758,53$ \\
\hline & & 40 & $1.850,67$ & 4.144 & $3.049,98$ \\
\hline & & 80 & $1.915,27$ & 3.501 & $2.576,74$ \\
\hline & & 120 & $1.979,86$ & 4.208 & $3.097,09$ \\
\hline \multirow{8}{*}{$\begin{array}{c}\text { Grade pesada } \\
\text { + grade } \\
\text { niveladora }\end{array}$} & \multirow{4}{*}{$\begin{array}{c}\text { Sem } \\
\text { inoculação }\end{array}$} & 0 & $1.874,70$ & 2.560 & $1.884,16$ \\
\hline & & 40 & $1.939,29$ & 2.288 & $1.683,97$ \\
\hline & & 80 & $2.003,89$ & 2.527 & $1.859,87$ \\
\hline & & 120 & $2.068,48$ & 2.393 & $1.761,25$ \\
\hline & \multirow{4}{*}{$\begin{array}{l}\text { Com } \\
\text { inoculação }\end{array}$} & 0 & $1.901,58$ & 3.023 & $2.224,93$ \\
\hline & & 40 & $1.966,17$ & 2.491 & $1.833,38$ \\
\hline & & 80 & $2.030,77$ & 2.821 & $2.076,26$ \\
\hline & & 120 & $2.095,36$ & 2.647 & $1.948,19$ \\
\hline
\end{tabular}

O lucro operacional e o índice de lucratividade no sistema plantio direto foram maiores nos tratamentos nas doses de 40 e $120 \mathrm{~kg}$ de N ha-1, independente da inoculação (Tabela 5). No preparo convencional apenas nos tratamentos sem inoculação com $0 \mathrm{~kg}$ de $\mathrm{N} \mathrm{ha}^{-1}$, com inoculação e com as doses de 0 e $80 \mathrm{~kg}$ de N $\mathrm{ha}^{-1}$ verificou-se valores positivos, porém menores que os observados no sistema plantio direto. No restante dos tratamentos no preparo convencional os valores foram 
negativos, indicando que não foi possível cobrir o custo operacional com a receita bruta.

O preço de equilíbrio, ou seja, o preço que é necessário ser recebido pelo produtor para que seja possível cobrir o COT, foi menor no sistema plantio direto, destacando os tratamentos na dose de 40 e $120 \mathrm{~kg}$ de $\mathrm{N} \mathrm{ha}^{-1}$, independente da inoculação. Os menores preços no preparo convencional foram observados nos tratamentos com inoculação de $A$. brasilense com adubação nas doses de 0 e $80 \mathrm{~kg}$ de $\mathrm{N} \mathrm{ha}^{-1}$, seguido pelos tratamentos com as mesmas doses, porém sem inoculação.

A produção de equilíbrio foi menor tanto no sistema plantio direto como no preparo convencional para as doses de 0 e $40 \mathrm{~kg}$ de $\mathrm{N} \mathrm{ha}^{-1}$, independente da inoculação, entretanto no sistema plantio direto foi inferior. Assim com essa menor produção é possível cobrir o COT.

TABELA 5. Lucro operacional (LO), índice de lucratividade (IL), preço de equilíbrio (PE), produtividade de equilíbrio (ProdE) por hectare para produção de arroz de terras altas com doses de nitrogênio e inoculação de $A$. brasilense. Selvíria, MS. Safra 2012/13.

\begin{tabular}{|c|c|c|c|c|c|c|}
\hline $\begin{array}{c}\text { Preparo do } \\
\text { solo }\end{array}$ & Tratamentos & $\begin{array}{l}\text { Doses } \\
\left(\mathrm{kg} \mathrm{ha}^{-1}\right)\end{array}$ & LO (R\$) & IL (\%) & $\begin{array}{c}\text { PE } \\
(R \$)\end{array}$ & $\begin{array}{c}\text { ProdE } \\
\text { (sacas) }\end{array}$ \\
\hline \multirow{8}{*}{$\begin{array}{c}\text { Sistema } \\
\text { Plantio Direto }\end{array}$} & \multirow{4}{*}{$\begin{array}{c}\text { Sem } \\
\text { inoculação }\end{array}$} & 0 & $1.036,13$ & 37 & 27,79 & 40 \\
\hline & & 40 & $1.271,09$ & 41 & 26,02 & 41 \\
\hline & & 80 & 751,64 & 28 & 31,59 & 43 \\
\hline & & 120 & $1.077,13$ & 36 & 28,46 & 44 \\
\hline & \multirow{4}{*}{$\begin{array}{c}\text { Com } \\
\text { inoculação }\end{array}$} & 0 & 972,45 & 35 & 28,59 & 40 \\
\hline & & 40 & $1.199,31$ & 39 & 26,80 & 42 \\
\hline & & 80 & 661,47 & 26 & 32,82 & 43 \\
\hline & & 120 & $1.117,22$ & 36 & 28,23 & 45 \\
\hline \multirow{8}{*}{$\begin{array}{c}\text { Grade pesada } \\
\text { + grade } \\
\text { niveladora }\end{array}$} & \multirow{4}{*}{$\begin{array}{c}\text { Sem } \\
\text { inoculação }\end{array}$} & 0 & 9,46 & 1 & 43,94 & 42 \\
\hline & & 40 & $-255,32$ & -15 & 50,86 & 44 \\
\hline & & 80 & $-144,02$ & -8 & 47,58 & 45 \\
\hline & & 120 & $-307,24$ & -17 & 51,86 & 47 \\
\hline & \multirow{4}{*}{$\begin{array}{c}\text { Com } \\
\text { inoculação }\end{array}$} & 0 & 323,35 & 15 & 37,74 & 43 \\
\hline & & 40 & $-132,80$ & -7 & 47,36 & 45 \\
\hline & & 80 & 45,49 & 2 & 43,19 & 46 \\
\hline & & 120 & $-147,17$ & -8 & 47,50 & 47 \\
\hline
\end{tabular}

\section{CONCLUSÕES}

Os custos são maiores quanto maior a dose de nitrogênio aplicada.

Os tratamentos mais rentáveis foram no sistema plantio direto com adubação nitrogenada na dose de $40 \mathrm{~kg} \mathrm{ha}^{-1}$ de $\mathrm{N}$ sem inoculação de Azospirillum brasilense na semente, seguida do tratamento com inoculação.

\section{AGRADECIMENTOS}

Os autores agradecem à FAPESP pelo financiamento da Pesquisa e a todos os funcionários da Fazenda de Ensino, Pesquisa e Extensão da UNESP- Ilha Solteira por auxiliarem no desenvolvimento da Pesquisa. 


\section{REFERÊNCIAS}

ACQUA, N.H.D.; SILVA, G.P.; BENITES, V.M.; ASSIS, R.L.; SIMON, G.A. Métodos de amostragem de solos em áreas sob plantio direto no Sudoeste Goiano. Revista Brasileira de Engenharia Agrícola e Ambiental, v.17, n.2, p. 117-122, 2013.

AGRIANUAL 2015: anuário da agricultura brasileira. São Paulo: Informa Economics South America/FNP, 2015. 472p.

ARF, O.; NASCIMENTO, V. DO; RODRIGUES, R. A. F.; ALVAREZ, R. DE C. F.; GITTI, D. DE C.; SÁ, M. E. de. Uso de etiltrinexapac em cultivares de arroz de terras altas. Pesquisa Agropecuária Tropical, v.42, n.2, p.150-158, 2012.

BASI, S.; NEUMANN, M.; MARAFON, F.; UENO, R.K.; SANDINI, I.E., Influência da adubação nitrogenada sobre a qualidade da silagem do milho. Revista Brasileira de Tecnologia Aplicada nas Ciências Agrárias, v.4, n.3, p.219-234, 2011.

COMPANHIA NACIONAL DE ABASTECIMENTO - CONAB. Acompanhamento da safra brasileira, grãos, V.2 - safra 2014/15, N.9 - Nono levantamento, Junho/2015. Brasília, 2015a. Disponível em: <http://www.conab.gov.br/OlalaCMS/uploads/arquivos/15_06_11_09_00_38_boletim _graos_junho_2015.pdf.> Acesso em: 23 junho 2015.

COMPANHIA NACIONAL DE ABASTECIMENTO - CONAB. Acompanhamento da safra brasileira: grãos, V.2- safra 2014/15, N.4 - Quarto levantamento, Janeiro/2015. Brasília, 2015b. Disponível em:

<http://www.conab.gov.br/OlalaCMS/uploads/arquivos/15_01_09_09_00_21_boletim _graos_janeiro_2015.pdf> Acesso em: 23 junho 2015.

DEMATTÊ, J. L. I. Levantamento detalhado dos solos do "Campus Experimental de Ilha Solteira". Piracicaba: Escola Superior de Agricultura Luiz de Queiroz, 1980. p.11-31.

EMPRESA BRASILEIRA DE PESQUISA AGROPECUÁRIA - EMBRAPA. Cultivo do arroz irrigado no Brasil: importância econômica, agrícola e alimentar do arroz. Sistemas de Produção, n.3, $2005 . \quad<$ Disponível em: http://sistemasdeproducao.cnptia.embrapa.br/FontesHTML/Arroz/ArrozlrrigadoBrasil/ cap01.htm> Acesso em: 4 setembro 2015.

EMPRESA BRASILEIRA DE PESQUISA AGROPECUÁRIA - EMBRAPA. Cultivo do Arroz de Terras Altas no Estado de Mato Grosso. Sistemas de Produção, n.7, 2006. Disponível em:

http://sistemasdeproducao.cnptia.embrapa.br/FontesHTML/Arroz/ArrozTerrasAltasM atoGrosso/preparo_solo_semeadura.htm> Acesso em: 30 agosto 2015.

EMPRESA BRASILEIRA DE PESQUISA AGROPECUÁRIA - EMBRAPA. Informações técnicas sobre o arroz de terras altas: Estados de Mato Grosso e Rondônia - safras 2009/2010 e 2010/2011. Embrapa Arroz e Feijão. 94 p. 2009. 
EMPRESA BRASILEIRA DE PESQUISA AGROPECUÁRIA - EMBRAPA. Sistema brasileiro de classificação de solos. 3. Ed. Brasília: Embrapa, 2013. 353p.

FANCELLI, A. L. Boas práticas para o uso eficiente de fertilizantes na cultura do milho. Piracicaba: International Plant Nutrition Institute Brazil, 2010. p.1-16. (Informações Agronômicas, 131).

FERREIRA, D. F. SISVAR: um programa para análises e ensino de estatística. Revista Symposium, v.6, p.36-41, 2008.

FONSECA, A. E.; ARF, O.; ORIOLI JÚNIOR, V.; BUZETTI, S.; RODRIGUES, R. A. F. Preparo do solo e doses de nitrogênio em cobertura em arroz de terras altas. Pesquisa Agropecuária Tropical, Goiania, v.42, n.3, p.246-253, 2012.

FOOD AND AGRICULTURE ORGANIZATION - FAO (2013). Faostat 2013: production crops. [S.I.: s.n.], 2013. Disponível em: <http://faostat.fao.org > Acesso em: 08 junho 2015.

INSTITUTO DE ECONOMIA AGRÍCOLA-IEA (2015) Banco de dados. Disponível em: < http://ciagri.iea.sp.gov.br/nia1/precos_medios.aspx?cod_sis=2> Acesso em: 25 maio 2015.

KHAN, F.U.H. e YULE, A.R.T.A.I.J. Intrinsic Implication of Different Tillage Practices on Soil Penetration Resistance and Crop Growth. International journal of agriculture \& biology, v.23, n.1, p 23-26, 2001.

MARTIN, N. B.; SERRA, R.; OLIVEIRA, M. D. M.; ANGELO, J. A.; OKAWA, H. Sistema integrado de custos agropecuários - CUSTAGRI. Informações Econômicas, São Paulo, v. 28, n. 1, p.7-28, 1998.

MATSUNAGA, M.; BEMELMANS, P.F.; TOLEDO, P.N.E.; DULLEY, R.D.; OKAWA, H.; PEDROSO, I.A. Metodologia de custo de produção utilizada pelo IEA. Agricultura em São Paulo, São Paulo, v.23, n.1, p.123-139, 1976.

MUZILLI, O. Gestão da fertilidade do solo em sistema de plantio direto. Plantio Direto com Qualidade, n.3, 2001.

SILVA, O. F.; WANDER, A. E. Viabilidade econômica do cultivar de arroz de terras altas BRS Sertaneja. Sociedade brasileira de economia, administração e sociologia rural. $52^{\circ}$ Congresso da SOBER . 2014.

SOARES, F.N. Leguminosas forrageiras. 2009. 36f. Trabalho de Conclusão de Curso (Graduação em Medicina Veterinária) - Universidade Federal do Pará UFPA, Castanhal. Disponível em: < http://br.monografias.com/trabalhospdf/leguminosas-forrageiras/leguminosas-forrageiras.pdf> Acesso em: 29 agosto 2015.

WANDER, A.E. Arroz em terras altas e reduzidas. A Granja, Porto Alegre, v.66, n.735, p.30-33, 2010. Disponível em: 
http://www.edcentaurus.com.br/materias/granja.php?id=2670> Acesso em: 08 junho 2015. 